\title{
Realización de audio como elemento complementario a la rehabilitación de personas privadas de la libertad
}

\section{Provision of audio as a complement to the rehabilitation of persons deprived of their liberty}

\author{
Wilson Gárate Andrade ${ }^{1}$ \\ ${ }^{1}$ Universidad de Cuenca, Ecuador \\ *wilson.garate@ucuenca.edu.ec
}

DOI: https://doi.org/10.26871/killkanasocial.v5i1.765

\begin{abstract}
Resumen
Dentro de las posibilidades que brinda el "Convenio marco suscrito entre el Ministerio de Justicia, Derechos Humanos y Cultos- MJDHC y la Universidad de Cuenca”; desde septiembre de 2014 se desarrolla el Plan de capacitación dirigido a los internos del Centro de Rehabilitación Social Integral Centro Sur, CRS Turi. Su finalidad es la elaboración de contenidos de realización de audio que estimulen el conocimiento de la gestión de medio radio y permita el ejercicio de los derechos de acceso y participación en la comunicación y de manera particular al derecho a emitir y recibir información. Todo en el marco de las libertades de pensamiento y de expresión. Se desarrolla al inicio de cada periodo académico universitario; en marzo y octubre con la colaboración de un grupo de estudiantes voluntarios de las carreras de Periodismo y Comunicación de la Facultad de Filosofía, Letras y Ciencias de la Comunicación Social, de la Universidad de Cuenca. Se trata de un proceso interactivo y participativo de generación de contenidos de comunicación ligados a reafirmar sus prácticas de valores.
\end{abstract}

Palabras clave: rehabilitación, narrativa transmedia, producción y realización de radio, vinculación con la sociedad, valores.

\begin{abstract}
Within the possibilities offered by the "Framework Agreement signed between the Ministry of Justice, Human Rights and Cults - MJDHC and the University of Cuenca"; Since September 2014, the Training Plan for Inmates of the Centro Social Rehabilitación Centro Sur Center, CRS Turi has been developed. Its purpose is the development of audio content that stimulates the knowledge of the management of radio media and allows the exercise of the rights of access and participation in communication and in particular the right to broadcast and receive information. All within the framework of freedom of thought and expression. It is developed at the beginning of each academic university period; in March and October with the collaboration of a group of student volunteers from the journalism and communication careers of the Faculty of Philosophy, Letters and Social Communication Sciences of the University of Cuenca. It is an interactive and participative process of generation of communication contents linked to the reaffirmation and practice of values.
\end{abstract}

Keywords: rehabilitation, transmedia narrative, radio production and production, relationship with society, values.

\section{Introducción}

El presente trabajo es una visión sistematizada del desarrollo y ejecución del proyecto de vinculación con la sociedad: Producción, realización, programación y promoción del programa Voces del Alma en el CRS Turi. El artículo recoge los antecedentes e importancia de la responsabilidad adquirida por profesores y estudiantes de la Carrera de Comunicación Social de la Universidad de Cuenca, universidad pública que con el proyecto de vinculación busca devolver a la sociedad acciones concretas en reciprocidad a su entorno inmediato y al cual la academia le debe su creación y crecimiento. También, enuncia estrategias metodológicas y técnicas didácticas empleadas en un proceso que se centra en la capacitación de personas privadas de la libertad, PPL, quienes participan en iniciativas de formación complementaria; en este caso puntual como participantes de los programas Voces del Alma y Sueños Infinitos. Para, finalmente advertir algunos de los logros de aprendizaje individuales y de aportes colaborativos bajo los lineamientos de la capacitación recibida en cada una de las sesiones de colaboración y de realización radial. 
La presente descripción del plan de trabajo se complementa con matrices de planificación de las sesiones semanales que se cumplen cada semestre de estudios, en una visión programada para taller interactivo que se desarrolla en modalidad asistida, con módulos previstos en unidades de trabajo que se cumplen en ocho a doce semanas.

Finalmente, en los casi cinco años que se desarrolla el proceso nos permite evidenciar resultados de aprendizaje manifiestos en la permanencia de productos comunicacionales que se han sumado a Voces del Alma, como el programa Sueños infinitos que se produce en el pabellón de mujeres y el espacio que se desarrolla para la radio de la Asamblea Nacional. También el aporte significativo que representa para los estudiantes de comunicación el involucramiento en las tareas de programación y conformación de grupos colaborativos. En sus testimonios y diarios de trabajo se advierten cambios positivos en sus actitudes y comportamientos frente a la situación de las personas en situación de vulnerabilidad; volviéndoles mejores personas y capaces

\section{Recuperación y práctica de valores}

Toda actividad humana se centra en la práctica de valores. Los valores, como los demás intereses y comportamientos de los seres humanos surgieron de la convivencia y de la generación de la cultura y la comunicación. (Eco, 2000)

Es por ello que los valores tanto para el mundo occidental y andino cuentan para ampliar las posibilidades de una convivencia en armonía con los otros y el entorno. Una práctica cotidiana de los valores universales hace posible y amigable la relación del hombre y su espacio; permite la movilidad, el respeto y la aceptación de la diversidad.

Es por estas y otras consideraciones, las narrativas de audio resultan de alto valor en la práctica y promoción de los principios universales de convivencia y la práctica de las garantías universales que hacen posible la aceptación e identificación con el otro. (Botello, 2018)

\subsection{SESIÓN UNO: Dinámica de construcción de valores}

\begin{tabular}{|c|c|c|}
\hline \multicolumn{2}{|l|}{ OBJETIVOS } & CONTENIDOS \\
\hline \multicolumn{2}{|c|}{$\begin{array}{l}\text { Los participantes PPL son capaces } \\
\text { de identificarse con la construcción } \\
\text { y práctica de valores humanos que } \\
\text { le permiten un ejercicio de confian- } \\
\text { za y confraternidad. }\end{array}$} & $\begin{array}{l}\text { Los valores humanos. } \\
\text { El significado del círculo y la ronda } \\
\text { como espacios para conocerse unos } \\
\text { a otros en igualdad de ubicación, } \\
\text { dirección y participación. }\end{array}$ \\
\hline ANTICIPACIÓN & $\begin{array}{l}\text { DESARROLLO DE CO- } \\
\text { NOCIMIENTOS }\end{array}$ & CONSOLIDACIÓN \\
\hline $\begin{array}{l}\text { Presentaciones } \\
\text { personales: } \\
\text { identificación con } \\
\text { valores. Alternar } \\
\text { con los ejercicios } \\
\text { de respiración para } \\
\text { mejorar la expresión } \\
\text { corporal y la oral. }\end{array}$ & $\begin{array}{l}\text { Los valores que cuen- } \\
\text { tan para una conviven- } \\
\text { cia armónica y solida- } \\
\text { ria. Ejercicio de memoria } \\
\text { para recordar la relación } \\
\text { de la identificación per- } \\
\text { sonal, nombre, el animal } \\
\text { con el cual nos identifi- } \\
\text { camos y el valor que lo } \\
\text { representa. }\end{array}$ & $\begin{array}{l}\text { Los participantes se iden- } \\
\text { tifican con sus valores. } \\
\text { Reafirman los propios y } \\
\text { empiezan a reconocerlos } \\
\text { en los otros. } \\
\text { Explican y hacen público } \\
\text { al exteriorizar los valores } \\
\text { que practican. }\end{array}$ \\
\hline
\end{tabular}

\subsection{SESIÓN DOS: Taller de claridad modulación de la voz}

La voz representa en el ser humano la posibilidad de comunicarse e interactuar con el otro. La oralidad significa también la manifestación de la simbología en la construcción de la palabra y sus usos y beneficios en la proximidad con los demás individuos de la especie humana.

Esa transición del gesto, el alarido, el gruñido a la articulación de palabras se pierde en los remotos confines de la prehistoria. Al parecer la anatomía, morfología de los órganos y la fisiología que hacen posible la emisión de la voz humana estaría dispuesta solamente ya con el hombre pensante. Aquel capaz de establecer diálogos y pensamiento con él mismo y con sus congéneres. Lo del inicio y desarrollo la escritura es mucho más reciente y precisa; pues los registros en arcilla y metales nos remiten a unos 6.000 años atrás, cuando los pueblos sumerios hicieron posible la transcripción del lenguaje oral al escrito y permitieron el registro de lo que hoy denominamos historia. (Morín, 2006)

La simbología, las palabras y las voces entonces pueden ser interpretadas para dos propósitos distintos y hasta opuestos: por una parte permitieron un mayor acercamiento y garantizar la perpetuidad entre semejantes y afines; y por otro, generaron discordia, distanciamiento y conflictos con quienes se concebían como extraños, diferentes, distintos. (Fernández, 2002)

Debemos pensar que el sueño humano nos guía al uso de la voz como posibilidad de acercamiento, de superación de diferencias y de una construcción distinta del comportamiento de los seres humanos con relación a los otros; y, el ser capaces de generar ambientes de armonía. Así es como se concibe este segundo momento de formación y capacitación.

\begin{tabular}{ll}
\hline OBJETIVOS & CONTENIDOS \\
\hline $\begin{array}{l}\text { Desarrollar las habilida- } \\
\text { des que se requieren para }\end{array}$ & $\begin{array}{l}\text { Presentación de contenidos: } \\
\text { Valorar la importancia del uso de la palabra y } \\
\text { hablar en público }\end{array}$ \\
& la expresión oral en la interactividad \\
& Los medios de comunicación \\
& El primer medio de comunicación la palabra, \\
& la expresión oral. \\
& De la palabra a la escritura \\
& La educación liberadora- es la recuperación \\
& de las actividades lúdicas. \\
& El origen de la educación en el "ludi \\
& magister", inspirado en el modelo griego. \\
& La necesidad de hablar en público- la \\
& aprensión en comunicación. \\
& Conocimiento habilidades y actitud \\
& La respiración diafragmática - Respirar- \\
pronunciar - vocalizar cada una de las & \\
& vocales. \\
& Estética de la expresión. Del habla local al \\
& estilo personal \\
\hline
\end{tabular}




\begin{tabular}{|c|c|c|}
\hline ANTICIPACIÓN & $\begin{array}{l}\text { DESARROLLO DE } \\
\text { CONOCIMIENTOS }\end{array}$ & CONSOLIDACIÓN \\
\hline $\begin{array}{l}\text { Presentación } \\
\text { del facilitador } \\
\text { charla } \\
\text { expositiva. }\end{array}$ & $\begin{array}{l}\text { Alternar con los ejercicios de res- } \\
\text { piración para mejorar la expresión } \\
\text { corporal y la oral. El "paedagogus- } \\
\text { actual pedagogo" encamina al niño } \\
\text { a la escuela. } \\
\text { "ars bene dicendi" el arte de expre- } \\
\text { sarse bien- Demóstenes. } \\
\text { ¿La educación es un juego? } \\
\text { Pronunciar con corrección y con es- } \\
\text { tética. } \\
\text { Los defectos en la pronunciación. } \\
\text { El respeto por el habla local. Los } \\
\text { dialectos. } \\
\text { Actividades prácticas: } \\
\text { Las vocales a, e, i, o, u } \\
\text { Las consonantes sílabas y palabras } \\
\text { de difícil pronunciación } \\
\text { Ra, re, ri, ro, ru } \\
\text { Bra, bre, bri, bro, bru } \\
\text { Bla, ble, bli, blo, blu. } \\
\text { Relación de la pronunciación con la } \\
\text { expresión corporal. } \\
\text { Seguridad- equilibrio } \\
\text { Las notas musicales: Do, Re, Mi. } \\
\text { Fa, Sol. La, Si. }\end{array}$ & $\begin{array}{l}\text { Los participantes se } \\
\text { familiarizan con los } \\
\text { conceptos y la utili- } \\
\text { dad del habla y de } \\
\text { una apropiada pro- } \\
\text { nunciación, vocali- } \\
\text { zación y articula- } \\
\text { ción de las palabras; } \\
\text { sobre todo de aque- } \\
\text { llas de difícil pro- } \\
\text { nunciación. }\end{array}$ \\
\hline
\end{tabular}

\subsection{SESIÓN TRES: Las sensaciones cuentan en las na- rrativas audiovisuales}

La radio juega con los sentidos. Los sonidos despiertan la imaginación y se asocian con facilidad a las "imágenes auditivas". Esas imágenes que se producen por las percepciones, táctiles, gustativas; olfativas y visuales hacen que los participantes desarrollen su imaginación y razonen a partir de objetos muy apreciados para ellos, a los cuales les otorgan cualidades, y en sus descripciones les asocien y relacionen con sus sensaciones, emociones y sentimientos. (Herreros, 2001)

$\mathrm{Y}$ es que primero son las sensaciones las que al individuo le permite, mediante la agudeza de sus sentidos el describir su entorno inmediato en todas y cada una de sus características; de las sensibilidades el paso a las reacciones emotivas unas tenues y otras particularmente intensas. Moldeadas las emociones por la cultura y el aprendizaje en la convivencia y la construcción de intereses y valores esos primeros estímulos y sus reacciones se transforman en sentimientos. Y, desde luego son los que cuentan los que trascienden a los demás a través de las palabras, los sonidos, la música y, la ausencia de estos recursos... los silencios.

\begin{tabular}{lll}
\hline OBJETIVOS & \multicolumn{1}{c}{ CONTENIDOS } \\
\hline $\begin{array}{l}\text { Los participantes están } \\
\text { en capacidad de gene- } \\
\text { rar relatos propios con el } \\
\text { desarrollo de su imagina- } \\
\text { ción. }\end{array}$ & $\begin{array}{l}\text { El relato: La percepción: la relación que se } \\
\text { sensaciones, emociones; } \\
\text { los sentimientos. las emociones con }\end{array}$ \\
\hline \multicolumn{4}{c}{ DESARROLLO DE } \\
\hline ANTICIPACIÓN & \multicolumn{1}{c}{ CONOCIMIENTOS } & CONSOLIDACIÓN \\
\hline $\begin{array}{l}\text { Juego para des- } \\
\text { pertar la imagi- } \\
\text { nación: }\end{array}$ & $\begin{array}{l}\text { De las percepciones a las emocio- } \\
\text { nes y a los sentimientos, el descu- } \\
\text { brimiento de una escala de pasos } \\
\text { razonados. }\end{array}$ & $\begin{array}{l}\text { Los adticipantes } \\
\text { redactan } \\
\text { monólogontes }\end{array}$ \\
$\begin{array}{l}\text { Tres } \\
\text { estrategias } \\
\text { de redacción: }\end{array}$ & $\begin{array}{l}\text { Redacción en primera persona } \\
\text { Redacción en segunda persona }\end{array}$ & \\
\hline
\end{tabular}

\subsection{SESIÓN CUATRO: Del monólogo al diálogo. La pro- sopopeya}

La prosopopeya se define como el recurso literario y narrativo que hace posible el atribuirle cualidades animadas a los objetos y atributos humanos a los objetos y a los animales. La posibilidad que permite que un candelabro ilumine un espacio y también le llene de encantadoras melodías y suaves palabras hechas canciones. Que un perro mantenga una larga conversación filosófica con un gato. Y que un búho sabio aconseje a un atormentado adolescente víctima de sus incontables incomprensiones.

La prosopopeya y personalización en las narraciones despierta la creatividad y la expande a las ilimitadas posibilidades de la creación de ficción.

\begin{tabular}{ll}
\hline OBJETIVOS & CONTENIDOS \\
\hline Comprender la prosopo- & Los recursos narrativos en la literatura \\
peya como un recurso li- & La estructura del cuento \\
terario que le brinda a & La importancia de los personajes \\
la narrativa la posibilidad & La prosopopeya y la personalización \\
de potencial la imagina- & \\
ción &
\end{tabular}

\begin{tabular}{|c|c|c|}
\hline ANTICIPACIÓN & $\begin{array}{l}\text { DESARROLLO DE } \\
\text { CONOCIMIENTOS }\end{array}$ & CONSOLIDACIÓN \\
\hline $\begin{array}{l}\text { La Prosopope- } \\
\text { ya como estra- } \\
\text { tegia del paso } \\
\text { del monólogo } \\
\text { al diálogo. }\end{array}$ & $\begin{array}{l}\text { Los estudiantes participantes gene- } \\
\text { ran sus personajes y los acompañan } \\
\text { y fortalecen con diálogos. }\end{array}$ & $\begin{array}{l}\text { Se genera un diálo- } \\
\text { go con los persona- } \\
\text { jes creados. }\end{array}$ \\
\hline $\begin{array}{l}\text { Nos hace falta } \\
\text { una historia }\end{array}$ & $\begin{array}{l}\text { Los aportes de los recursos litera- } \\
\text { rios: la estructura del cuento. Tra- } \\
\text { ma, nudo y desenlace. }\end{array}$ & $\begin{array}{l}\text { El trabajo de grupos } \\
\text { genera una historia } \\
\text { en la que los perso- } \\
\text { najes creados inter- } \\
\text { cambian sus recur- } \\
\text { sos. }\end{array}$ \\
\hline $\begin{array}{l}\text { Cómo se crea } \\
\text { un personaje: } \\
\text { Lluvia de ideas }\end{array}$ & $\begin{array}{l}\text { Personaje, en radio puede ser un ob- } \\
\text { jeto en diferencia con el documental } \\
\text { que es un ser humano. } \\
\text { Las relaciones que se establecen } \\
\text { entre los personajes: Protagonista, } \\
\text { antagonista, asistentes o ayudantes, } \\
\text { coprotagonistas. }\end{array}$ & $\begin{array}{lr}\text { La historia empieza } & \text { interés } \\
\text { cobrar } & \text { alrededor de una } \\
\text { alrérica o } & \text { una } \\
\text { temática } & \\
\text { trama. } & \\
\text { Los participantes } \\
\text { comparten r los } \\
\text { resultados y } r e \\
\text { escuchan } \\
\text { trabajos. }\end{array}$ \\
\hline
\end{tabular}

\subsection{SESIÓN CINCO: De la práctica de valores a la participación}

Argumentación: Una vez aprobadas las cuatro primeras sesiones de trabajo y con un suficiente ensayo en redacción y construcción de personajes; los participantes están en capacidad de construir sus propias historias.

\begin{tabular}{ll}
\hline OBJETIVOS & CONTENIDOS \\
\hline Los participantes están & El valor de la narración y la transmisión oral \\
en capacidad de gene- & de los relatos con sentido. \\
rar relatos propios con el & El relato, La percepción, la relación que se \\
desarrollo de su imagina- & establece entre la realidad, la imaginación, las \\
ción. & sensaciones, emociones; y, las emociones con \\
Los estudiantes graban & los sentimientos. Todo esto presente en los \\
sus relatos con la partici- & relatos son expresados con claridad y soltura. \\
pación de personajes de & \\
ficción. & \\
\hline
\end{tabular}




\begin{tabular}{|c|c|c|}
\hline ANTICIPACIÓN & $\begin{array}{l}\text { DESARROLLO DE } \\
\text { CONOCIMIENTOS }\end{array}$ & CONSOLIDACIÓN \\
\hline $\begin{array}{l}\text { Refuerzo de la } \\
\text { sesión } 1 \\
\text { Juego de } \\
\text { la ronda: } \\
\text { ejercicios de } \\
\text { vocalización, } \\
\text { entonación, } \\
\text { claridad y } \\
\text { énfasis. } \\
\text { Los ejercicios } \\
\text { de respiración } \\
\text { para mejorar } \\
\text { la expresión } \\
\text { corporal y la } \\
\text { oral. } \\
\text { Juego para } \\
\text { despertar la } \\
\text { imaginación. } \\
\text { Preparación de } \\
\text { relatos para la } \\
\text { grabación. }\end{array}$ & $\begin{array}{l}\text { Los valores que cuentan para una } \\
\text { convivencia armónica y solidaria } \\
\text { son colocados en los relatos de cada } \\
\text { uno de los grupos. } \\
\text { De las percepciones a las emocio- } \\
\text { nes y a los sentimientos, el descu- } \\
\text { brimiento de una escala de pasos } \\
\text { razonados. }\end{array}$ & $\begin{array}{l}\text { Los participantes re- } \\
\text { dactan y graban sus } \\
\text { relatos con la con- } \\
\text { figuración de per- } \\
\text { sonajes que recrean } \\
\text { valores, emociones, } \\
\text { sensaciones y senti- } \\
\text { mientos. }\end{array}$ \\
\hline $\begin{array}{l}\text { Refuerzo de la } \\
\text { sesión } 2 \\
\text { Estrategia del } \\
\text { paso del monó- } \\
\text { logo al diálogo } \\
\text { y del diálogo a } \\
\text { la historia. }\end{array}$ & $\begin{array}{l}\text { Los participantes generan sus per- } \\
\text { sonajes y los acompañan y forta- } \\
\text { lecen con diálogos en historias en } \\
\text { las cuales se identifica al personaje } \\
\text { central, principal, a los ayudantes y } \\
\text { asistentes. Los protagonistas y co- } \\
\text { protagonistas. }\end{array}$ & $\begin{array}{l}\text { Se genera un diálo- } \\
\text { go con los persona- } \\
\text { jes creados. Se re- } \\
\text { crean historias y se } \\
\text { cuentan }\end{array}$ \\
\hline $\begin{array}{l}\text { Refuerzo de } \\
\text { sesión } 3 \\
\text { Nos hace falta } \\
\text { una historia }\end{array}$ & $\begin{array}{l}\text { Los aportes de los recursos litera- } \\
\text { rios: la estructura del cuento. Tra- } \\
\text { ma, nudo y desenlace. }\end{array}$ & $\begin{array}{l}\text { El trabajo de grupos } \\
\text { genera una historia } \\
\text { en la que los perso- } \\
\text { najes creados inter- } \\
\text { cambian sus recur- } \\
\text { sos. Todos estos re- } \\
\text { cursos aparecen en } \\
\text { las grabaciones. }\end{array}$ \\
\hline $\begin{array}{l}\text { Refuerzo de } \\
\text { sesión } 4 \\
\text { Cómo se crea } \\
\text { un personaje: } \\
\text { Lluvia de } \\
\text { ideas, entre los } \\
\text { participantes. }\end{array}$ & $\begin{array}{l}\text { Cada estudiante representa a su per- } \\
\text { sonaje. Personaje, en radio puede } \\
\text { ser un objeto en diferencia con el } \\
\text { documental que es un ser humano. } \\
\text { Las relaciones que se establecen } \\
\text { entre los personajes: Protagonista, } \\
\text { antagonista, asistentes o ayudantes, } \\
\text { coprotagonistas. }\end{array}$ & $\begin{array}{l}\text { La historia es redac- } \\
\text { tada y leída. }\end{array}$ \\
\hline
\end{tabular}

\subsection{SESIÓN SEIS: PRIMERA PARTE. La noticia: breve y ampliada}

Si la comunicación nos facilita la interactividad y la proximidad con los otros; la información permite la recreación de la realidad y la construcción de la verdad. El tratamiento informativo de los hechos, sucesos y acontecimientos exige el conocimiento de ciertas habilidades en el uso del discurso noticioso. Es por ello que se propone como elemento básico un dominio mínimo de la estructura de la noticia, en las dimensiones de redaccón breve de un párrafo; como de la posinbilidad de una construcción ampliada con la indaganción de antecedentes, consecuencias e indentificación de los responsables. También es exigencia que el estudiante puede diferenciar la narración informativa noticiosa sobre la realidad y la verdad; de aquella que se corresponde con la literaria y de ficción; como de aquellla cuya pretención es la persuasión en la opinión, la propaganda y la publicidad.

\begin{tabular}{ll}
\hline OBJETIVOS & CONTENIDOS \\
\hline $\begin{array}{l}\text { Que los estudiantes desa- } \\
\text { rrollen habilidades para }\end{array}$ & El lenguaje literario, lenguaje informativo y \\
la identificación y redac- & Diferencia entre realidad y ficción \\
$\begin{array}{l}\text { ción de noticias breves, } \\
\text { sobre temas de relevancia }\end{array}$ & Los géneros informativos \\
social e interés público. & \\
\hline
\end{tabular}

\begin{tabular}{|c|c|c|}
\hline ANTICIPACIÓN & $\begin{array}{l}\text { DESARROLLO DE } \\
\text { CONOCIMIENTOS }\end{array}$ & CONSOLIDACIÓN \\
\hline $\begin{array}{l}\text { Los } \\
\text { facilitadores } \\
\text { leen las } \\
\text { noticias } \\
\text { del día. Se } \\
\text { leen dos o } \\
\text { tres noticias } \\
\text { relacionadas } \\
\text { con las } \\
\text { actividades } \\
\text { del CRS Turi } \\
\text { para que } \\
\text { aprendan a } \\
\text { reconocer la } \\
\text { proximidad y } \\
\text { distancia de las } \\
\text { noticias }\end{array}$ & $\begin{array}{l}\text { Los lenguajes literario, informativo } \\
\text { y persuasivo. } \\
\text { Los géneros literarios: Narrativo, lí- } \\
\text { rico, dramático: cuento, novela, en- } \\
\text { sayo, poesía, teatro. } \\
\text { Lenguaje persuasivo: publicidad y } \\
\text { la propaganda. } \\
\text { Lenguaje periodístico: géneros pe- } \\
\text { riodísticos/ la noticia breve y am- } \\
\text { pliada. } \\
\text { Antecedentes, desarrollo, conse- } \\
\text { cuencias. }\end{array}$ & $\begin{array}{l}\text { Los estudiantes es- } \\
\text { criben noticias cor- } \\
\text { tas e indagan en } \\
\text { lo posible antece- } \\
\text { dentes y consecuen- } \\
\text { cias, e identifican } \\
\text { responsables. }\end{array}$ \\
\hline
\end{tabular}

\subsection{SESIÓN SEIS: SEGUNDA PARTE. La entrevista: un diálogo prolongado y deliberado}

El diálogo es el género y estilo por excelencia de la realización de audio para radio. Y la conversación sobre aspectos deliberados y planificacdos recibe la denominación de entrevista. La entrevista conceptualizada como el diálogo con una o varias personas sobre una problemática o asusnto convenido y deliberado enriquece la producción y realización de radio.

La entrevista tiene un complemento indispensable, la investigación. Y el poder de la sistematización de la experiencia que brida el acceder a fuentes de consulta confiables. Ya sea que recojamos declaraciones testimoniales de participantes directos de los acontecimientos, como de acadèmicos, expertos o especialistas.

\begin{tabular}{|c|c|c|c|}
\hline \multicolumn{2}{|l|}{ OBJETIVOS } & \multicolumn{2}{|l|}{ CONTENIDOS } \\
\hline \multicolumn{2}{|c|}{$\begin{array}{l}\text { Los participantes son ca- } \\
\text { paces de comprender la } \\
\text { dinámica de un diálogo } \\
\text { extendido o entrevista. }\end{array}$} & \multicolumn{2}{|c|}{$\begin{array}{l}\text { Del diálogo a la entrevista deliberada } \\
\text { La planificación del antes, durante y después. }\end{array}$} \\
\hline \multicolumn{4}{|c|}{ CONOCIMIENTOS } \\
\hline La entrevista & $\begin{array}{l}\text { Tipos de } \\
\text { Ejercicio } \\
\text { La planifi } \\
\text { El antes, }\end{array}$ & $\begin{array}{l}\text { trevista } \\
\text { ráctico de entrevista } \\
\text { ación de la entrevista } \\
\text { urante y después. }\end{array}$ & $\begin{array}{l}\text { Los estudiantes ha- } \\
\text { cen simulaciones de } \\
\text { entrevistas. }\end{array}$ \\
\hline $\begin{array}{l}\text { La entrevista } \\
\text { para } \\
\text { complementar } \\
\text { noticias. }\end{array}$ & $\begin{array}{l}\text { Distinciór } \\
\text { cabar test } \\
\text { expertos, } \\
\text { tas. }\end{array}$ & $\begin{array}{l}\text { entre entrevista para re- } \\
\text { nonios de la entrevista de } \\
\text { cadémicos y especialis- }\end{array}$ & $\begin{array}{l}\text { Entrevistas simula- } \\
\text { das }\end{array}$ \\
\hline $\begin{array}{l}\text { Los estilos de } \\
\text { entrevista: }\end{array}$ & $\begin{array}{l}\text { Entrevista } \\
\text { Entrevista } \\
\text { comillas } \\
\text { Entrevista } \\
\text { fraseo } \\
\text { Entrevista }\end{array}$ & $\begin{array}{l}\text { de citas textuales entre- } \\
\text { interpretativa con para- } \\
\text { pregunta respuesta }\end{array}$ & $\begin{array}{l}\text { Entrevistas planifi- } \\
\text { cadas }\end{array}$ \\
\hline
\end{tabular}

\subsection{SESIÓN SIETE: Taller de planos auditivos e imáge- nes visuales}

Argumentación: La radio, como medio, mediante la utilización de los sonidos, genera imágenes auditivas cuenta con el soporte simbólico de las palabras; y, en el desarrollo alcanzado por el lenguaje radiofónico con los complementos que le facilitan la música, los efectos sonoros y silencios; es un medio que se ha insertado perfectamente en 
la multimedialidad, la convergencia y en la actualidad en las potencialidades y aplicaciones que permiten las narrativas audiovisuales transmedia.

Para cualquier pretensión de trabajo en radio se deben aprovechar los complementos que brinda el internet con sus herramientas y aplicaciones.

\begin{tabular}{|c|c|c|c|}
\hline \multicolumn{2}{|l|}{ OBJETIVOS } & \multicolumn{2}{|l|}{ CONTENIDOS } \\
\hline \multicolumn{2}{|c|}{$\begin{array}{l}\text { Los participantes son ca- } \\
\text { paces de conceptualizar } \\
\text { las imágenes auditivas y } \\
\text { de cómo se pueden des- } \\
\text { cribir entornos con los } \\
\text { sonidos en relación a la } \\
\text { distancia del micrófono. }\end{array}$} & \multicolumn{2}{|c|}{$\begin{array}{l}\text { Breve historia y fundamentos de las imágenes } \\
\text { visuales. La transición de los primeros planos } \\
\text { sonoros a los medios y distantes. } \\
\text { Los planos como elementos primarios del len- } \\
\text { guaje radiofónico. } \\
\text { Planos cercanos, medios y lejanos. }\end{array}$} \\
\hline \multicolumn{4}{|c|}{ CONOCIMIENTOS } \\
\hline $\begin{array}{l}\text { Concibe los } \\
\text { plano sonoros } \\
\text { de acuerdo a } \\
\text { la distancia del } \\
\text { objeto emisor } \\
\text { de sonidos y } \\
\text { el micrófono. } \\
\text { Como el } \\
\text { espacio de } \\
\text { representación } \\
\text { de la realidad. } \\
\text { Describe las } \\
\text { características } \\
\text { y utilidad de } \\
\text { cada uno de } \\
\text { los planos } \\
\text { sonoros: } \\
\text { distancia, } \\
\text { proximidad. } \\
\text { Analiza la } \\
\text { importancia } \\
\text { de las } \\
\text { estrategias de } \\
\text { composición } \\
\text { de los sonidos. }\end{array}$ & $\begin{array}{l}\text { Primeros } \\
\text { planos ge } \\
\text { Expresivc } \\
\text { vos. } \\
\text { Las estrat } \\
\text { Elemento } \\
\text { ción: Los } \\
\text { o eje de } \\
\text { ción, o ej } \\
\text { vencia o } \\
\text { Las func } \\
\text { enunciati } \\
\text { va; descr } \\
\text { va; ornan } \\
\text { mentativa } \\
\text { cios práct }\end{array}$ & $\begin{array}{l}\text { planos, planos medios, } \\
\text { erales panorámicos. } \\
\text { de acción y descripti- } \\
\text { gias de composición. } \\
\text { sonoros de composi- } \\
\text { jes del montaje: sucesión } \\
\text { uxtaposición; superposi- } \\
\text { de simultaneidad. Disol- } \\
\text { e de alternancia. } \\
\text { nes de cada elemento: } \\
\text { - informativa- expositi- } \\
\text { tiva, narrativa, expresi- } \\
\text { ntal, programática, argu- } \\
\text { y comunicativa. Ejerci- } \\
\text { oos. }\end{array}$ & $\begin{array}{l}\text { El valor de los } \\
\text { complementos de } \\
\text { la música, efectos } \\
\text { sonoros y silencios. } \\
\text { Lectura de } \\
\text { imágenes auditivas, } \\
\text { los tres planos sobre } \\
\text { la construcción } \\
\text { de acuerdo a la } \\
\text { distancia. } \\
\text { El estudiante en } \\
\text { trabajo en grupos } \\
\text { delinea la estructura } \\
\text { del guión, con } \\
\text { sus personajes: } \\
\text { monólogos, } \\
\text { diálogos y } \\
\text { dramatizados; } \\
\text { en los que evidencia } \\
\text { el empleo de los } \\
\text { elementos sonoros: } \\
\text { palabra, música, } \\
\text { efectos y silencios. }\end{array}$ \\
\hline
\end{tabular}

\subsection{SESIÓN OCHO: Taller de teatro y expresión corporal}

Argumentación: El estado físico, la expresión corporal, la actuación son recursos complementarios indispensables en la formación del realizador y presentador de radio; es por ello que su aprendizaje, formación y cultivo cotidiano resultan de alto beneficio en la capacitación. La personalización y representación de personajes resulta clave en el dramatizado para radio. Así como todo el aprendizaje requerido para ponerlo en escena.

\begin{tabular}{|c|c|c|c|}
\hline \multicolumn{2}{|l|}{ OBJETIVOS } & \multicolumn{2}{|l|}{ CONTENIDOS } \\
\hline \multicolumn{2}{|c|}{$\begin{array}{lr}\text { Desarrollar } & \text { habilidades } \\
\text { para representar y } \\
\text { escenificar diferentes } \\
\text { situaciones. }\end{array}$} & \multicolumn{2}{|c|}{$\begin{array}{l}\text { Respiración } \\
\text { Reconocimiento corporal } \\
\text { Relación realidad aparente con realidad repre- } \\
\text { sentada } \\
\text { Los juegos y posibilidades de la improvisa- } \\
\text { ción en la representación. Libertad de movi- } \\
\text { miento y de acciones. }\end{array}$} \\
\hline \multicolumn{4}{|c|}{$\begin{array}{l}\text { DESARROLLO DE } \\
\text { CONOCIMIENTOS }\end{array}$} \\
\hline $\begin{array}{l}\text { La ronda: } \\
\text { todos nos } \\
\text { miramos todos } \\
\text { caminamos. } \\
\text { Si eres capaz } \\
\text { de moverte } \\
\text { puedes actuar }\end{array}$ & $\begin{array}{l}\text { Presentac } \\
\text { Jornada: } \\
\text { de los int } \\
\text { yo } \\
\text { Ejercicio } \\
\text { presión c } \\
\text { Tensión } \\
\text { Observac }\end{array}$ & $\begin{array}{l}\text { n de Contenidos de la } \\
\text { esentaciones personales } \\
\text { rantes del grupo de apo- } \\
\text { de calentamiento y ex- } \\
\text { poral } \\
\text { listensión. } \\
\text { n y participación. }\end{array}$ & $\begin{array}{l}\text { Seguimiento } \\
\text { de consignas, } \\
\text { disciplina, orden, } \\
\text { silencio. } \\
\text { Representaciones } \\
\text { individuales y } \\
\text { juegos de roles } \\
\text { en actividades } \\
\text { grupales. }\end{array}$ \\
\hline
\end{tabular}

\section{Conclusiones y recomendaciones}

El CRS TURI alberga una población de PPL superior a las 3.000 personas. De las cuales un mínimo porcentaje participa de las actividades de educación regular y complementaria. Cada semestre el programa de Vinculación con la Colectividad Voces del Alma en el CRS TURI capacita a 60 PPL en dos grupos de trabajo, con dos sesiones semanales.

Los resultados son de alta satisfacción en cuanto a cambios de comportamiento, en el sentido de asimilación de nuevos conocimientos y manejo de herramientas y destrezas para la producción y realización de radio.

El complemento en la formación de una reafirmación de valores e intereses se manifiesta, de manera evidente en las producciones radiales.

Hay cada vez mayor expectativa de las estaciones de radio, locales, regionales y cadenas nacionales y de redes de radios internacionales por radiodifundir las realizaciones de Voces del Alma y Sueños Infinitos.

Para los estudiantes universitarios de comunicación y periodismo significa una oportunidad única para vincularse con actividades de solidaridad y apoyo a un grupo de población vulnerable.

\section{Referencias Bibliográficas}

Botello, J. R. (2018). Ética periodística en la era digital. Washington: UNESCO.

Eco, U. (2000). Tratado de semiótica general. Barcelona, España: Lumen.

Fernández, F. (2002). Civilizaciones: La lucha del hombre por controlar la naturaleza. Londres: TAURUS.

Herreros, M. C. (2001). La radio en la convergencia multimedia. Barcelona: Gedisa.

Morín, E. (2006). Breve historia de la barbarie en occidente. Buenos Aires: PAIDOS.

Recibido: 4 de julio de 2020

Aceptado: 14 de diciembre de 2020 
